Cahiers d'études africaines

$204 \mid 2011$

Varia

\title{
Garnier, Xavier. - Le roman swahili, la notion de littérature mineure à l'épreuve
}

\section{Anthony Mangeon}

\section{OpenEdition}

1 Journals

Édition électronique

URL : http://journals.openedition.org/etudesafricaines/14318

DOI : 10.4000/etudesafricaines. 14318

ISSN : 1777-5353

Éditeur

Éditions de l'EHESS

\section{Édition imprimée}

Date de publication : 23 novembre 2011

Pagination : 1012-1014

ISBN : 978-2-7132-2299-3

ISSN : 0008-0055

Référence électronique

Anthony Mangeon, « Garnier, Xavier. - Le roman swahili, la notion de littérature mineure à l'épreuve », Cahiers d'études africaines [En ligne], 204 | 2011, mis en ligne le 16 décembre 2011, consulté le 23 septembre 2020. URL : http://journals.openedition.org/etudesafricaines/14318; DOI : https://doi.org/ 10.4000/etudesafricaines.14318

Ce document a été généré automatiquement le 23 septembre 2020.

(c) Cahiers d'Études africaines 


\section{Garnier, Xavier. - Le roman swahili, la notion de littérature mineure à l'épreuve} Anthony Mangeon

\section{RÉFÉRENCE}

GARNIER, Xavier. - Le roman swahili, la notion de littérature mineure à l'épreuve. Paris, Karthala, 2006, 243 p., bibl.

1 Pierre Alexandre, l'un des fondateurs des Cahiers d'Études africaines, fut longtemps en France l'un des rares africanistes à étudier la langue et les littératures swahilies ${ }^{1}$. Parce qu'il s'intéressait, lui aussi, aux productions littéraires dans les langues africaines, Alain Ricard lui emboîta le pas dès les années $1990^{2}$, bientôt rejoint par Xavier Garnier avec qui il anima, à l'Inalco, un séminaire sur les «premiers romans » dans diverses langues africaines ${ }^{3}$. Cette monographie sur Le roman swahili s'inscrit donc dans un champ en pleine expansion, depuis quelques années, avec notamment un projet ANR en cours (" dimensions de l'objet swahili : textes et terrains »). Mais surtout, elle prend acte des profondes mutations qu'a introduites « l'émergence de la fiction en prose dans la très ancienne littérature swahilie, [...] en relation étroite avec l'aventure politique dans laquelle s'engage l'Afrique de l'Est, et en particulier la Tanzanie, vers le milieu du xx siècle » (p. 5).

Pour explorer ce lien entre littérature et politique dans ses expressions swahilies, Xavier Garnier s'appuie sur les écrits théoriques de divers critiques et écrivains tanzaniens, qu'il articule à la notion de "littérature mineure " élaborée par Gilles Deleuze et Félix Guattari à partir des réflexions de Franz Kafka sur les «petites littératures " (Journal, 1954 ; Kafka, 1975). Ce qui caractérise en effet une "littérature mineure ", ce n'est pas seulement «l'usage d'une langue majeure » au service d'une minorité dominée, ce sont surtout « la déterritorialisation, la dimension collective et la 
dimension politique» (p.7). Si le kiswahili peut être, aujourd'hui, considéré comme " une langue moderne » parce que "standardisée, utilisée dans la vie courante, capable de dire le monde technique, indépendante des religions et des nations particulières $»^{4}$, cette standardisation/modernisation, qui fut tour à tour la préoccupation des autorités coloniales puis des États africains indépendants, reste finalement récente et sa réalisation fut adossée dès le départ à la constitution d'un " corpus de textes en proses " (p.11). Il s'ensuit donc, au niveau de la littérature, une postulation contradictoire, puisque d'une part les écrivains swahilis auront, nous montre Garnier, « une tendance naturelle à déterritorialiser le kiswahili » (p. 11) et à « malmener la langue à leur façon dans leurs œuvres » (p. 13) tandis qu'ils voudront, d'autre part, pleinement contribuer à construire de nouvelles sociétés en les "révélant " par les textes - ce que Garnier rapporte au concept deleuzien d'« agencement collectif d'énonciation » (p. 20).

L'ouvrage alterne, de fait, les chapitres généraux et les approches monographiques (sur Shaaban Robert, Euphrase Kezilahabi, Mohamed Suleiman, Said Ahmed Mohamed). Le premier chapitre explore une tension, héritée de l'époque coloniale, entre la nécessité ethnographique de "raconter des valeurs » et celle, politique, de "décrire un monde » ouvert sur l'extérieur. "La filiation» et "l'alliance» s'imposent comme les deux réponses du roman swahili aux problèmes de la survie civilisationnelle («comment franchir l'obstacle de la succession des générations? Comment survivre au contact d'autres mondes?», [p. 31]). Nombre de romans s'offrent ainsi, sur le modèle des contes, comme l'illustration d'une règle de vie généralement résumée par un proverbe qui sert alors de titre (pp. 33-35), tandis que d'autres se focalisent sur « les événements sociaux : naissances, mariages, enterrements » (p. 37) qui nouent et dénouent les liens $\mathrm{du}$ « système familial » avec le monde des ancêtres ou celui du « dehors » (p. 38). «Le souci ethnographique affiché, de rendre compte d'un mode de vie swahili menacé par la colonisation et la vie moderne, est dès l'origine doublé d'un regard centrifuge porté sur le monde extérieur » (p. 59), obligeant le roman à se chercher un territoire ailleurs que dans la langue : «dans la réalité »(p. 61). Shabaan Robert (1909-1962) apparaît alors comme «le grand opérateur de ce changement de régime pour l'écriture narrative »: le chapitre II lui est entièrement consacré, qui explore le motif du déménagement et les "mécanismes de la gloire» comme deux ressorts narratifs essentiels dans l'œuvre fictionnelle et autobiographique de l'écrivain tanzanien. Après un chapitre consacré à «la crise du roman de formation", c'est le "réalisme initiatique " de Kezilahabi qui sert de contrepoint, puisque chez lui toute trame narrative se tisse sur la question d'élargir le cercle intime ou d'en sortir pour refonder l'ordre social. Le chapitre $\mathrm{V}$ est tout entier dévoué au "roman politique », dans sa fidélité à la fable (héros inébranlables, "personnages plats») et aux mots d'ordre du socialisme africain. L'œuvre de Mohamed Suleiman s'impose alors comme une autre manière de refuser le réel au bénéfice d'un idéal à poursuivre plus encore qu'à réaliser : ses récits «se terminent le plus souvent par une fuite en avant, une échappée, une disparition» (p. 145). D'autres, a contrario, font du roman populaire la voie du triste retour à la réalité, « en explorant les bas-fonds de la réalité sociale, aux antipodes de la fable et de ses personnages-types idéaux» (p.158). Le chapitre VII propose ainsi l'inventaire des «criminels et des corrompus" qui peuplent la littérature swahilie moderne, selon deux orientations : «Les romans qui mettent en scène des criminels dessinent en creux la vitalité d'une société capable de circonscrire ces crimes, les romans de la corruption racontent une société en voie de déliquescence» (p. 168). Un chapitre distinct est ensuite consacré au roman policier, genre fort populaire et 
dynamique en Afrique de l'Est. Après un dernier essai sur les différents régimes de l'image dans l'œuvre de Said Ahmed Mohamed, la conclusion revient sur la question des littératures mineures en interrogeant, à partir de Kafka et des récits présentés au fil de l'ouvrage, la question des rapports entre peuple et littérature. Écrire le peuple, écrire au peuple, écrire pour le peuple: "L'ajustement entre littérature savante et littérature s'est fait progressivement» autour de ces enjeux (p.222), tandis que l'absence d'un domaine littéraire autonome, indépendant des sphères sociale et politique, a joué paradoxalement une fonction émancipatrice : «La littérature swahilie n'est pas une littérature de "maîtres". Il n'existe pas de statues littéraires à déboulonner pour poser des avant-gardes. [...] Chaque romancier semble contraint d'être son propre maître, de se faire son propre nom. [...] Le roman populaire est un roman d'auteurs. [...] L'absence de modèles nationaux indiscutables ouvre cette littérature à des influences internationales tous azimuts. [...] L'intensité de la vie littéraire swahilie est en prise directe sur la partie la plus vivante de la création littéraire mondiale » (pp. 223-224).

4 Au moment où Jean Bessière portait un sévère diagnostic sur l'état de la littérature française, l'accusant de " cécité face à la réalité » et lui préférant le dynamisme des littératures dites francophones 5 , au moment où des écrivains africains s'alliaient à des auteurs français pour promouvoir un nouveau courant dit de "la littérature-monde ", " ouverte sur le monde et soucieuse de le dire ${ }^{6}$, l'ouvrage de Xavier Garnier ajoutait une nouvelle dimension au comparatisme littéraire en nous faisant sortir de préoccupations franco-centrées et en découvrant ce pan pour nous méconnu de la production littéraire africaine qui constitue de fait, selon ses propres termes, "un inconscient des théories postcoloniales $\aleph^{7}$. Ce livre, basé sur plus de 175 romans swahilis écrits par près de 100 auteurs, constitue une somme qui fait honneur à ce continent ignoré des lettres africaines, et l'indifférence dans laquelle l'a tenue à son tour la critique devrait connaitre un terme avec sa traduction prochaine en anglais.

\section{NOTES}

1. Voir notamment Langues et langage en Afrique noire, Paris, Payot, 1967, et sa chronique bibliographique, « Kiswahili alakati », Cahiers d'Études africaines, XXIV (1), 93, 1984, pp. 101-104.

2. Littératures d'Afrique noire, des langues aux livres, Paris, Karthala, 1995, et Ebrahim HUSSEIN, Théâtre swahili et nationalisme tanzanien, Paris, Karthala, 1998.

3. L'effet roman : arrivée du roman dans les langues d'Afrique, Paris, L'Harmattan, 2006.

4. Alain RICARD, Le Kiswahili, une langue moderne, Paris, Karthala, 2009, p. 6.

5. Qu'est-il arrivé aux écrivains français? D’Alain Robbe-Grillet à Jonathan Littell, Loverdal, Éditions Labor («Liberté j'écris ton nom »), 2006.

6. Michel LE BRIS \& Jean ROUAUD (dir.), Pour une littérature-monde, Paris, Gallimard, 2007.

7. Xavier GARNIER, «Les littératures en langues africaines ou l'inconscient des théories postcoloniales ", Neohelicon, XXXV (2), 2008, pp. 87-99. 